\title{
Bernard DOMPNIER, Paola VISMARA (compil.), Confréries et dévotions dans la catholicité moderne (mi-XV ${ }^{\mathrm{e}}$ siècle-début XIX ${ }^{\mathrm{e}}$ siècle)
}

Rome, École française de Rome, coll. « Publications de l'EFR », 293, 2008, $442 \mathrm{p}$.

\section{Bruno Maes}

\section{OpenEdition}

Journals

\section{Édition électronique}

URL : http://journals.openedition.org/assr/21556

DOI : $10.4000 /$ assr.21556

ISSN : $1777-5825$

Éditeur

Éditions de l'EHESS

\section{Édition imprimée}

Date de publication : 31 décembre 2009

Pagination : 75-342

ISBN : 978-2-7132-2218-4

ISSN : 0335-5985

Référence électronique

Bruno Maes, «Bernard dompnier, Paola vismara (compil.), Confréries et dévotions dans la catholicité moderne (mi-xv siècle-début xıx ${ }^{\mathrm{e}}$ siècle) ", Archives de sciences sociales des religions [En ligne], 148| octobre-décembre 2009, document 148-43, mis en ligne le 27 janvier 2010, consulté le 21 septembre 2020. URL : http://journals.openedition.org/assr/21556 ; DOI : https://doi.org/10.4000/assr.21556

Ce document a été généré automatiquement le 21 septembre 2020.

(c) Archives de sciences sociales des religions 


\section{Bernard DOMPNIER, Paola VISMARA (compil.), Confréries et dévotions dans la catholicité moderne $\left(\mathrm{mi}-\mathrm{XV}^{\mathrm{e}}\right.$ siècle-début XIX ${ }^{\mathrm{e}}$ siècle)}

Rome, École française de Rome, coll. « Publications de l'EFR », 293, 2008, $442 \mathrm{p}$.

\section{Bruno Maes}

\section{RÉFÉRENCE}

Bernard DOMPNIER, Paola VISMARA (compil.), Confréries et dévotions dans la catholicité moderne (mi-Xve siècle-début XIX siècle), Rome, École française de Rome, coll.

«Publications de l'EFR », 293, 2008, 442 p.

1 Cet ouvrage publie les dix-huit communications d'un colloque tenu à Rome, en octobre 2003, à l'initiative du Centre d'histoire «Espaces et cultures» (Université Blaise Pascal de Clermont-Ferrand), de l'Università degli studi de Milan, et du Centre d'anthropologie religieuse européenne (EHESS), avec la collaboration de l'École française de Rome.

2 Il porte sur les confréries, de l'âge des réformes au début du xix siècle. Ces associations de laïcs - qui existaient déjà au Moyen Âge - visent à partir de l'époque moderne à un approfondissement de la démarche religieuse personnelle, et à un renforcement des règles $d u$ comportement $d u$ chrétien. Un rapport évident existe entre l'important développement des sodalités laïques et le profond processus de rénovation de l'Église à la suite du concile de Trente auquel elles contribuent comme force d'innovation sur le plan religieux et dans le domaine de l'engagement social. 
3 Le but de ce colloque est de faire un bilan historiographique de l'état de la question afin d'ouvrir des perspectives de recherches et de proposer de nouvelles approches pour l'avenir.

4 Pour mieux entrer dans ce colloque il faut commencer par lire le texte final des deux organisateurs. En faisant un bilan des recherches, il donne une grille qui permet de mieux comprendre les communications. C'est le doyen Le Bras qui a posé les premiers jalons de ces études dès 1940, mais leur véritable essor ne commence que vingt ans plus tard avec le triomphe de la sociologie religieuse rétrospective où elles sont perçues comme un bon indicateur de la piété des laïcs. Dans les premières études on privilégiait les sources locales (visites pastorales, registres de comptabilité et d'entrées). Depuis une vingtaine d'années, la palette des sources s'est élargie avec l'imprimé et les documents romains (brefs d'indulgences). Si les sources se sont élargies, surtout en France et en Italie, il en va de même des entrées dans celles-ci: le disciplinamento, ou les études sur les enjeux politiques des cultes locaux ou nationaux, permettent de les traiter différemment.

5 Un mérite de ce colloque est de traiter de lieux variés (Europe, Orient, continent américain...), d'époques différentes, d'outils et de supports nouveaux (livres, images, chants) et de thèmes de dévotion divers (Saint-Sacrement, Saint-Joseph, indulgences, de la Bonne Mort) pour mieux présenter le spectre de la situation actuelle.

Une communication méthodologique essentielle (R. Bertrand) montre que l'existence d'une confrérie en Provence ne diffuse pas toujours le rayonnement de sa dévotion, car elle peut être à recrutement sélectif, dans le cadre d'une confrérie de métier, par exemple. Nous observons dans l'axe rhénan - une frontière de catholicité - que les confréries marquent chez les catholiques un attachement à Rome (L. Châtellier). Une large part est faite aux dévotions: S.Simiz analyse les rapports à l'indulgence qui avaient été à l'origine de la réforme luthérienne; G.Sinicropi étudie les confréries carmélitaines dans la France des $\mathrm{XVII}^{\mathrm{e}}$ et $\mathrm{XVIII}^{\mathrm{e}}$ siècles; P.Desmette se penche sur les sodalités du diocèse de Cambrai; F.Hernandez sur les associations de la Bonne Mort et B.Dompnier sur celles de saint Joseph, patron des ménages et de la sainte famille, qui insistent sur la prière privée et sur la possession d'une image. Les espaces périphériques ne sont pas oubliés: B.Heyberger étudie un phénomène nouveau au XVII ${ }^{\mathrm{e}}$ siècle, les confréries apportées en terre musulmane par les missionnaires latins, qui favorisent l'intériorisation de la croyance par des livrets en arabe; l'espace ibérique est étudié par P.Ragon, spécialiste du Mexique, et par B.Vincent, sur les centaines de confréries de Noirs à qui elles servaient de lieu de sociabilité. L'évolution du livre de confrérie (M.-H. Froeschlé-Chopard, P. Martin) montre aussi l'évolution de la fonction du phénomène confraternel: au XvII ${ }^{e}$ siècle, il a encore un rôle d'affirmation d'identité catholique face aux protestants, alors qu'au siècle des Lumières il devient un manuel de dévotion nécessaire à la spiritualisation du quotidien, tout comme les Wallfahrtsbüchlein ou livrets de pèlerinages alsaciens à la même époque. Enfin, une dernière entrée, plus anthropologique, concerne le «son» des confréries où S.Nanni se penche sur les prières et chants des parcours processionnels, sans oublier le tintement des cloches et l'éclat des trompettes.

7 Au total, sachons gré aux organisateurs de ce colloque d'avoir fait un bon bilan d'un demi-siècle d'étude du phénomène confraternel, et d'avoir ouvert des perspectives de recherches aussi diverses que prometteuses. 